\title{
Optogenetics and photopharmacology in pain research and therapeutics
}

\author{
Federico ISEPPON ${ }^{\mathrm{a}, \mathrm{b}^{*}}$, and Manuel ARCANGELETTI ${ }^{\mathrm{a}}$ \\ ${ }^{a}$ Molecular Nociception Group, Wolfson Institute for Biomedical Research, University College London, Gower Street, WC1E 6BT, London, UK \\ ${ }^{b}$ Discovery UK, Neuroscience, Biopharmaceuticals R\&D, AstraZeneca, Cambridge, UK. \\ ${ }^{*}$ Correspondence: f.iseppon@ucl.ac.uk \\ https://doi.org/10.37175/stemedicine.v1i3.43
}

\begin{abstract}
Pain afflicts billions of people worldwide, who suffer especially from long-term chronic pain. This gruelling condition affects the nervous system at all levels: from the brain to the spinal cord, the Dorsal Root Ganglia and the peripheral fibres innervating the skin. The nature of the different molecular and cellular components of the somatosensory modalities, as well as the complexity of the peripheral and central circuitry are yet poorly understood. Light-based techniques such as optogenetics, in concert with the recent advances in single-cell genetic profiling, can help to elucidate the role of diverse neuronal subpopulations in the encoding of different sensory and painful stimuli by switching these neurons on and off via optically active proteins, namely opsins. Recently, photopharmacology has emerged from the efforts made to advance optogenetics. The introduction of azo-benzene-based light-sensitive molecular switches has been applied to a plethora of molecular targets, from ion channels and receptors to transporters, enzymes and many more, some of which are paramount for pain research and therapy.

In this review, we summarise the past and ongoing research in the fields of optogenetics and photopharmacology and we discuss the use of light-based techniques for the investigation of acute and chronic pain physiology, besides their potential for future therapeutic use to improve pain treatment.
\end{abstract}

Keywords: Optogenetics · Photopharmacology · Pain · Phototherapy

\section{Introduction}

Pain, according to the International Association for the Study of Pain, is defined as "an unpleasant sensory and emotional experience associated with actual or potential tissue damage, or described in terms of such damage" (1). It is a condition that torments more than 1.5 billion people globally, who suffer especially from long-term chronic pain (2). Chronic pain indeed affects an estimated 20\% of adults in Europe and U.S., and the current available treatments produce limited reliefs and moderate to severe side effects $(2,3)$.

In contrast to many neurological disorders, pain affects the nervous system at all levels: from brain regions to spinal cord, Dorsal Root Ganglia (DRGs) and peripheral fibres that innervate the skin and the organs (4). Noxious sensation is mediated through the transmission of sensory

Received: Apr 20, 2020; Accepted: Jun 12, 2020.

(c) The Author(s). 2020 This is an Open Access article distributed under the terms of the Creative Commons License (http://creativecommons.org/licenses/by/4.0/) which permits unrestricted use, distribution, and reproduction in any medium or format, provided the original work is properly cited. inputs from the periphery to the spinal cord via modalityspecific afferents that reside in the DRGs and discriminate between the different tissue damaging stimuli $(4,5)$. Furthermore, the different nature of pain sensations (mechanical, thermal, chemical) is also dependent on the integration of the sensory inputs in the dorsal horn of the spinal cord, and abnormalities at any level lead to several pathological conditions, including chronic pain (6-9).

Albeit in the last few years technological advances have shed new light on the different molecular and cellular components of painful sensation, the precise circuitry, as well as the changes that occur in pathological conditions, remain not fully understood.

Genetic profiling of single neurons in the peripheral and central nervous systems has allowed the distinction of different sub-populations of sensory neurons based on specific molecular and cellular markers and may serve as a catalogue of the molecular and chemical bases of somatic sensation and pain (10).

Recently, the development and use of light-based approaches that aim to modulate these neurons and dissect the role of each sub-population in the encoding 
of the different painful stimuli grew exponentially. Optogenetics offers powerful genetic tools to analyse the function of these distinct cellular circuits (11), while photopharmacology is focused on the modulation of channels and receptors that are differentially expressed throughout the nervous system and paramount for pain input transmission with precise spatial and temporal resolution $(12,13)$.

This article aims to review the recent literature on lightbased techniques and their applications for research on acute and chronic pain physiology.

\section{Origin and development of light-based pharmacological approaches}

Optogenetics and photopharmacology are techniques that enable precise spatial and temporal control of the activity of specific sub-population of neurons. Optogenetics involves the use of genetically encoded light-sensitive ion channels whose sensitivity is dependent on chromophores of natural origin, such as retinal or flavins, in order to modulate cellular activity within specific cell types (14).

Photopharmacology, on the other hand, adopts entirely synthetic photoswitches, that are exogenous and need to be specifically delivered to control the function of native biological targets $(15,16)$. Such compounds need to have the capability to undergo a conformational change upon the delivery of a light stimulus and the physiological activities of these two forms must differ (17).

The development of both optogenetics and photopharmacology is inevitably linked: the first step in the development of optogenetics was the discovery by Stoeckenius and Oesterhelt, in 1971, of the light-sensitive ion channel bacteriorhodopsin. Bacteriorhodopsin is a proton pump driven by green light (maximum activation at $568 \mathrm{~nm}$ wavelength) that is used for photosynthesis in archaeon Halobacterium halobium (18). Six years later, in 1977, halorhodopsin (HR), an inhibitory, yellow lightsensitive chloride channel was discovered by MatsunoYagi and Mukohata (19). However, optogenetics as biotechnology was not established until 2002, when Hegemann and Nagel discovered in green algae the channelrhodopsin (ChR), an excitatory cation channel activated by blue light (20). Concurrently, in a paper published in 2002, Miesenbock showed that light could be used as a tool to stimulate action potential discharge in genetically localised neuron subpopulations (21). Later, in 2005, it was then demonstrated by the same group that light-driven activation of diverse circuits in the brain had a direct effect on animal behaviour in Drosophila melanogaster (22). In 2004 Kramer, Trauner and Isacoff applied a chemical optogenetic approach to render voltage-gated potassium channels responsive to light and thus controlling the on-off activity of neurons in culture (23). In 2005, ChR was then used to evoke action potentials in mammalian neurons (11) and from 2007 scientists started to use optogenetics as a tool in live, freely-moving animals (24). Successively, from 2012 onwards, a series of important advancements were made in this field: firstly, the design of red-shifted opsins allowed to use red light wavelengths to reduce scattering in tissues and improve both the efficiency and the spatial depth of the excitation $(25,26)$. Secondly, in 2014, Berndt and colleagues engineered an inhibitory isoform of channelrhodopsin-2 (ChR2), capable of conducting chloride anions instead of monovalent cations (27). Thirdly, extremely relevant for the purpose of this review was the development in 2016 of a bi-stable variant, stepwaveform inhibitory channelrhodopsin (SwiChR): this isoform is capable of long-lasting activation upon a brief exposure to blue light and deactivates promptly when illuminated with red light $(28,29)$. Besides ion channels, the continuous improvement of the optogenetic tools has brought to the engineering of chimeric light-sensitive G Protein Coupled Receptors (GPCR) called OptoXRs, that are capable, upon light exposure, of activating the intracellular signalling pathways as efficiently as their endogenous versions (30). Moreover, other components of subcellular signalling have been made light-sensitive: enzymes such as photoactivated adenylyl cyclase, light-oxygen-voltage sensors that facilitate proteinprotein interactions, and finally gene expression factors such as photoactivatable Cre recombinase (14,31). These advancements greatly expand the complexity of intracellular modulation beyond the simple on-off switch of the first rhodopsin-based opsins (32).

Photopharmacology originated as an effort to provide more reliable tools to optogenetics and in the last few years has grown noticeably due to its applicability in living systems and its role in complementing the conventional optogenetic techniques. The first breakthrough in this area dated as early as the 1960s, when Erlanger and Nachmansohn investigated azobenzene-based inhibitors of acetylcholinesterase $(33,34)$. However, it was only back in 2012 that Trauner and Kramer matured the idea of developing drugs containing synthetic light-switching molecules. The molecule they synthesized, specifically, was a diethylamine-azobenzene-quaternary ammonium able to replicate the light switching function of opsins by blocking the cell potassium-ion channels when activated by light and unblocking the channels in the dark $(35,36)$. Since then, chemistry in couple with biology have offered a wide variety of synthetic photoswitches with highly convertible properties targeted to ion channels, GPCRs, transporters, enzymes, cytoskeleton proteins and lipids, just to name some $(15,37)$.

\section{Designing probes for light-based research and therapy \\ Optogenetics}

Optogenetics, as mentioned before, is a technique that mainly exploits light-sensitive ion channels, the so-called opsins, to modulate neuronal activity with high spatial and temporal resolution (38). Excitatory opsins, like ChR2, are cation selective channels that cause cation influx and photo-controlled neuron depolarisation when illuminated at blue wavelengths (Figure 1A) $(11,20,39)$. 
Inhibitory opsins, like Archaeorhodopsin (Arch) or HR, provoke either proton efflux or chloride influx respectively to drive an outward photocurrent that generates hyperpolarisation and promptly inhibits neuronal activity (Figure 1B) (40-42). In recent years, the endeavour in genome screening and molecular engineering to expand the optogenetics toolbox has generated faster recovery variant for high-speed imaging $(43,44)$, red-shifted opsins to improve the depth of the light penetration $(45,46)$, and bi-stable opsin variants to induce long-lasting changes in neuronal activity. These latter variants are particularly interesting from a therapeutic point of view, since their capability to induce chronic effects with minimal light delivery would reduce both the need for constant light treatment and the risk of long-term phototoxicity (47).

Moreover, recent works focused on the modulation of intracellular signalling cascades with the engineering of photo-activatable cell-surfaced GPCRs for adrenergic, serotoninergic, dopaminergic, adenosine, glutamate (metabotropic) and $\mu$-opioid receptors $(30,48-52)$. These new OptoXR probes, as they are called, generate the same signalling cascade as the endogenous receptors, whilst they can be triggered with a spatio-temporal precision that is not achievable with traditional pharmacological approaches, thus bringing great advantage in the study of relevant targets in defined regions of the body (Figure 1C). This level of precise spatio-temporal control, particularly in the case of $\mu$-opioid receptors, is fundamental in dissecting the opioid contribution in peripheral and central nociceptive circuits (53).

The investigation of somatosensation and pain with optogenetics goes unavoidably in pair with the possibility to deliver the opsins to defined neuronal sub-populations in the central and peripheral nervous systems. Two approaches have
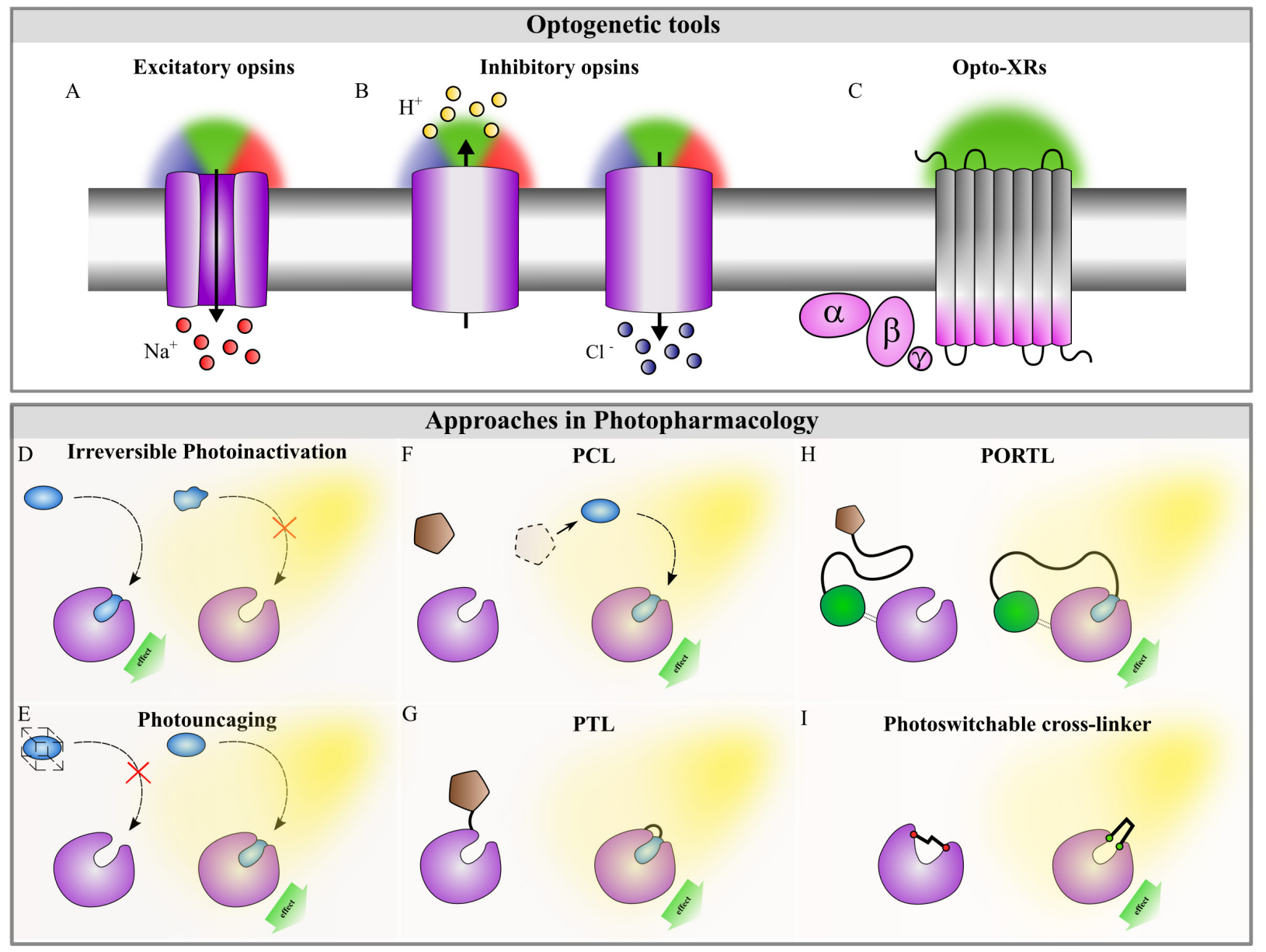

Figure 1. Optogenetic toolbox and Photopharmacological approaches. (A-C) Principal opsins used as optogenetic tools are illustrated. Arrows indicate direction of ion flux. (A) Excitatory opsins (ChR2) are non-specific cation channels that depolarize neurons when stimulated by light. (B) Inhibitory opsins elicit either chloride influx (iC1C2, SwiChR, ChloC, HR, Jaws) or proton efflux (Arch) to silence the neuronal activity when illuminated by light. (C) Chimeric light-sensitive G-protein coupled receptors (optoXRs), consisting of the extracellular and transmembrane domains of light-sensitive rhodopsins with the intracellular regions of a GPCR of interest. (D-I) Diverse Photopharmacological approaches are illustrated. Red crosses indicate the switch to the inactive conformation of the photomodulators. (D) Irreversible photoinactivation. (E) Irreversible photoactivation (photouncaging). (F) Reversible photoactivation/ inactivation using a PhotoChromic diffusible Ligand (PCL) that upon irradiation switches between an inactive (brown pentagon) and an active (blue ellipse) form, modulating the activity of the target. (G) Photo-switchable (closely) Tethered Ligand (PTL) - the photoswitch is, in this case, covalently bound to the target and in close proximity of it. $(\mathrm{H})$ Photo-switchable Orthogonal Remotely Tethered Ligand (PORTL) - As for the PTL, the photoswitch is connected to the target but is not in proximity of it. (I) Photo-switchable cross-linker - the photoswitch is conjugated on both sides to the target and usually prevents the activity of the target in one of its conformations. 
been the most utilised in tackling this issue: viral vectors and opsin-expressing transgenic mice (54-56). The specificity of the viral transgene delivery can be obtained mainly via incorporation of endogenous promoters (57) or recombinase-dependent expression $(58,59)$. Given the experimental problems that can arise with the former method, as well as its partial lack of specificity, the most widely used method for opsin gene delivery is the Cre/Lox-P mediated recombination and conditional expression of transgenes delivered by Adeno-Associated Viruses (AAVs) (60-62). These viruses are injected locally into transgenic mice in which the Cre recombinase expression is restricted to specific neuronal sub-populations (62-64). Conversely, crossing Cre-expressing mice with opsinexpressing lines gives yet another possibility to manipulate molecularly defined sets of neuronal and non-neuronal cells (65-67). These strategies are very advantageous in the study of large cell populations, that however can still comprise heterogeneous sub-populations with different functions within them. Thus, a novel approach called INTRSECT that uses multiple recombinase steps to further refine the specificity of selected subpopulations offers new advantages and great prospect for the study of neuronal circuits underlying specific roles in somatosensation and pain at all levels in the nervous system (68-71).

\section{Photopharmacology}

One of the main principles at the basis of photopharmacology is the ability to modulate the pharmacokinetic or pharmacodynamic properties of synthetic molecules by using light. This can be achieved, in most of the cases, with the alteration of a functional group of the drug with a photolysable element (72-74). The main benefit of using this technique is that it permits to reduce the offtarget and systemic side effects and to decrease the drug resistance in comparison to a standard drug delivery method (15). Photopharmacological tools have been previously applied to study cancer, diabetes, microbial infections and neurology $(15,16,75-81)$. The importance of this method derives from the fact that potentially every kind of molecule, even with very different range of sizes, can be optically-controlled and thus allowing a fine temporal and spatial control over intracellular or extracellular targets (82).

The effect that the light exerts on its target can be classified into two modalities: reversible and irreversible; each of them have been employed in biology (83).

Irreversible photoinactivation is realized when a freely diffusible compound is irreversibly modified by irradiation and has been mainly used to probe the functional role of a biological target (Figure 1D) (84). Also, caged compounds belong to this first category of molecules: they can only be activated once and the chemical strategy approach to gain photocontrol of a target by using these molecules is called photouncaging. Technically, a photocage is a chemical group that converts the energy of a photon into energy that is then used to disrupt a chemical bond, strategically placed in a position in which it can modulate the activity of a bioactive molecule (74). Irradiation promotes a reaction that causes the removal of the photocage, triggering the release of the biologically active molecule, switching on (or off) the targeted process (Figure 1E) (85). To date, this is the most broadly used photopharmacological approach, and several new photocages continue to appear $(73,74,86,87)$. The other approaches worth mentioning are the recent development of the so-called Photobody (87), that uses the specificity of an antibody fragment to selectively bind and modulate the activity of the desired target, and the family of BODIPY-derived photocages (86); the latter are caged compounds that can be activated with the highest known wavelengths of light through a mechanism that involves a single-photon-release.

As mentioned before, the major drawback of this technique is that the photouncaging process is irreversible and allows to control the properties of a pharmacological compound just once.

Reversible photoswitches, on the basis of the position relative to their target, can be classified into those that interact with their targets through noncovalent interactions (photo-chromic ligands - PCLs) and the ones in which the formation of a covalent bond is involved for the connection to the target (photo-switchable tethered ligands - PTLs, photo-switchable orthogonal remotely tethered ligands - PORTLs). There is also another class of reversible photoswitches, called cross-linkers, that rely on the aid of bioconjugation motifs at both sides of an optically active molecule.

PCLs are freely diffusible molecules in which the irradiation triggers the switch between two different isomeric conformations. As already mentioned, the switch into two different isoforms confers each of them different affinity and/or efficacy, diverse pharmacodynamics properties and may also affect the pharmacokinetics properties. (Figure 1F) (13).

A second class of reversible photoswitches includes ligands that are covalently attached to the target through a connection that can be either through a native or an engineered residue. Major advantages of this approach include the ability to accelerate the response by increasing the local concentration of the switches, the ability of the ligand to remain in the proximity of the target and the loss of the need for reapplication of the drug. On the other hand, this approach requires genetic encoding for its full applicability (88).

As mentioned before, tethered ligands can be sub-classified into (1) Photo-switchable Tethered Ligands (PTLs) and (2) Photo-switchable Orthogonal Remotely Tethered Ligands (PORTLs), depending on the length of the covalent attachment with respect to the ligand binding site.

In respect of PTLs, the photoswitch is attached close to the binding site and the tether is mainly constituted by the photoswitch itself. The switch between the different isomers mainly modifies the concentration of the pharmacophore in the near proximity of the target. They are ideally built as if in one configuration the ligand is physically impeded to reach the binding site while in the other it can exert its function. It requires small bioconjugation molecules, like cysteines (Figure 1G). 
Conversely, in a PORTL, the tether is much longer, bringing the photoswitch far from the binding site. In this way, the light-induced conformational change affects the efficacy of the tethered ligand rather than its local concentration near the target (Figure 1H) (89).

Another class is constituted by light-responsive crosslinkers in which the photoswitch is attached by a covalent bond on both its ends to the target. This method requires the presence of two conjugation motifs on the biomolecule. Upon irradiation, the photoswitch modifies its conformation, triggering then a change in the activity and conformation of the target itself (Figure 1I) $(13,16,75)$.

\section{Further considerations on designing photoswitches}

An ideal photoswitch must fulfil several requirements to be used in an in vivo model: it should have favourable pharmacokinetics and should be metabolically stable in a given environment. Phototoxicity is an important parameter to bear in mind and, in addition, the photoswitch should have useful photophysical properties, such as high absorbance and quantum yields, and useful thermal relaxation rates (13). A wide range of photoswitches have been used in the last few years but one of the most encouraging one, in terms of its properties, is the reversible molecule called azobenzene. Azobenzene is constituted by a diazo bond $(\boldsymbol{N}==\boldsymbol{N})$ that is linked to two phenyl rings. It can adopt the trans- or cis-conformation: in the former, the phenyl rings are on the opposite sides while in the latter, they are on the same side. UV light triggers the swap between the two isomers of which the trans- one is thermodynamically more stable. This process is reversible and can be inverted using heat or by using visible light irradiation $(13,35,36,90)$.

\section{Biological targets in pain research}

Pain is an extremely intricate disease which can progress into severe conditions. The effective treatment of pain often lacks the desired level of efficacy, tolerability and target specificity. Optogenetics in the last two decades had a pivotal role in the investigation of pain physiology both in the central and peripheral nervous systems (84). Photopharmacology emerged in the recent years as a potential new approach to be applied in pain research and treatment (91). In this section, we pass into exam all the development in pain research and the potential biological targets that have been unravelled with the aid of these approaches.

Within few years of demonstrating optical control of neuronal cells via ChR2, optogenetic probes were applied in vivo, together with surgically implanted optical fibres, to control and study different neural circuits within the brain. This idea has been recently implemented also in the investigation of the central circuits of both the sensory and the affective components of nociception $(92,93)$. In the cortico-limbic networks, the BasoLateral Amygdala (BLA) has been revealed to have a prominent role in the encoding of the 'unpleasantness' of pain (94). The sensory information from the BLA is transmitted to the medial PreFrontal Cortex (mPFC). ChR2 injection in the BLA revealed direct connectivity that was inputspecific, and the stimulation of these neurons in rodent models of chronic pain revealed increased feed-forward inhibition by mPFC GABAergic neurons (95). Moreover, the activation of the parvalbumin-positive GABAergic interneurons of the $\mathrm{mPFC}$ exacerbated pain responses after peripheral nerve injury, and conversely their inhibition alleviated these responses (96). These data reveal that persistent chronic pain states, provoked by peripheral nerve injuries, lead to a selective activation of BLA inputs on specific mPFC GABAergic interneurons, that in turn inhibit projection neurons in the ventro-lateral PeriAqueductal Gray area (vlPAG): this alteration produces a serial dysfunction of the inhibitory tone of the circuit itself, reducing the strength of serotoninergic and noradrenergic descending pathways involved in pain modulation (Figure 2A) $(96,97)$.

Anatomical and physiological evidence has been collected to demonstrate the presence of a circuit between ParaBrachial Nucleus (PBN) and the Central nucleus of the Amygdala $(\mathrm{CeA})$ and its role in the affective dimension of pain (98-100). Excitatory synapses within this circuit are potentiated in various chronic pain models $(99,101-103)$, and direct excitation of $\mathrm{CeA}$ neurons with $\mathrm{ChR} 2$ induced visceral hyperalgesia after bladder distension (102). Moreover, the investigation of the mechanisms involved in neuropathic pain revealed the presence of a complex modulation (both excitation and inhibition) of the neurons within this circuit, based both on specific molecular identity of the neurons and on their location within different subregions of the CeA (Figure 2A) (103). Together, these results offer a minor but precise overview of some of the complexity of the circuits that process both the sensory and affective component of pain within the brain, and how paramount is optogenetics to elucidate the role of single projections and specific neuronal subpopulations in the central processing of nociceptive information.

On the other hand, pain perception, as well as the processing of pain information, starts from the periphery, with the nociceptive stimuli travelling through a plethora of sub-populations of sensory neurons in the DRGs to the substantia gelatinosa (laminae I and II) of the dorsal horn (Figure 2B) $(5,104)$. A recent article identified 11 neuronal sub-populations by single-cell RNA sequencing, highlighting the complexity of the peripheral coding of multi-modal somatosensation (10). Optogenetics is therefore extremely useful in dissecting the role of these different populations in the coding of sensory and nociceptive inputs (105).

The first peripheral neurons targeted with ChR2 excitatory opsin were Mas-related G-protein coupled receptor member D (Mrgprd)-positive nociceptive neurons: their photostimulation revealed the circuitry of their connections to most known classes of lamina II spinal cord neurons (106). Light-dependent activation of Advillin-positive, Transient Receptor Potential Vanilloid 1 (TRPV1)-positive and NaV1.8-positive neurons selectively expressing ChR2 elicited strong nociceptive behaviours, which could be blocked by analgesics administration, indicating that a direct activation of these neuronal sub-populations is 


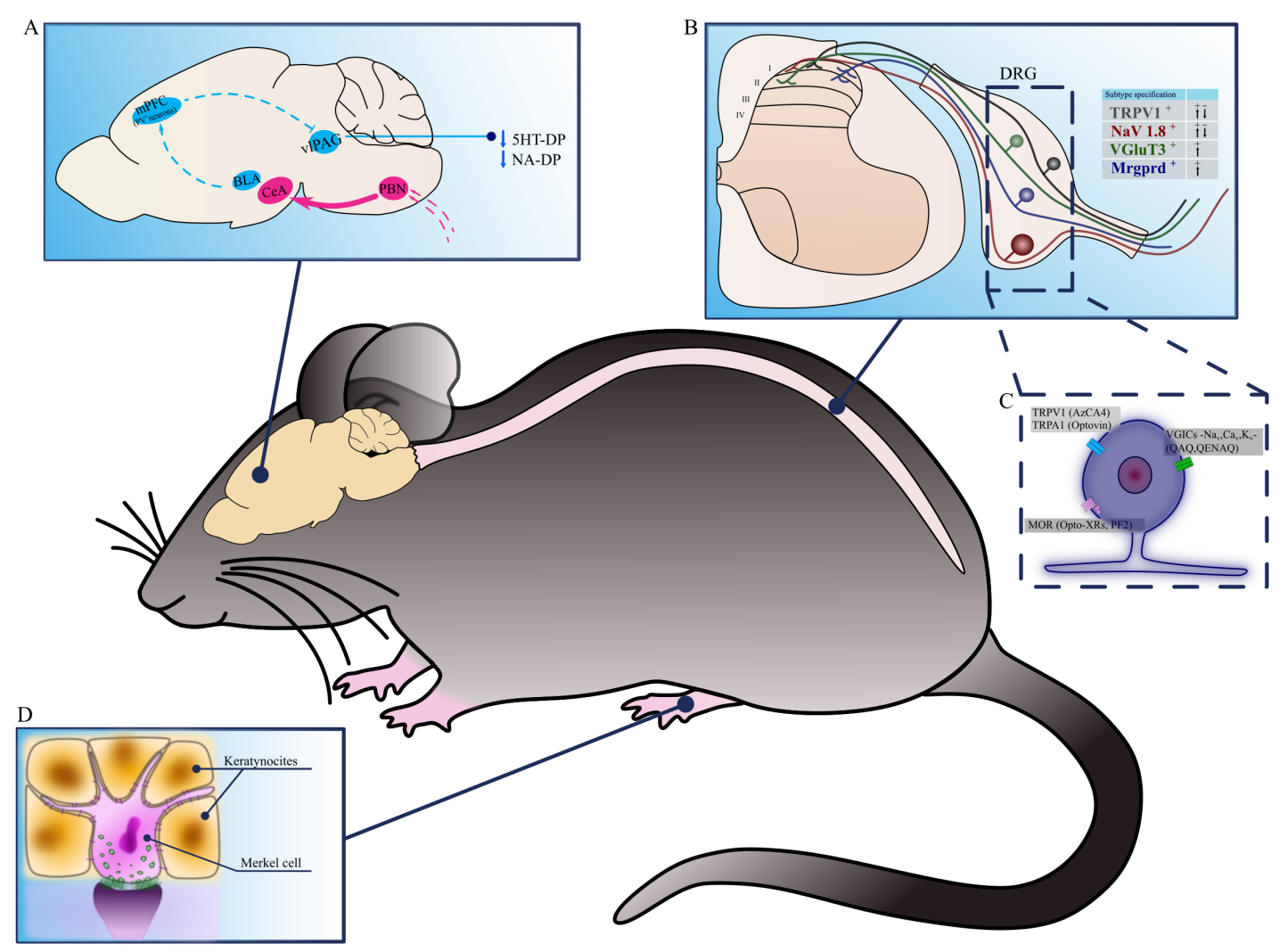

Figure 2. Biological targets of optogenetics and photopharmacology in pain research. Cartoon illustrating some of the targets of interest in the Central and Peripheral Nervous Systems, discussed in this review. (A) Overview of some neural circuits of pain within the brain. In light blue it is shown the pathway involving the basolateral amygdala $(B L A)$, the medial prefrontal cortex $(m P F C)$ and the ventro-lateral PeriAqueductal Gray area (VIPAG). The use of optogenetic tools has demonstrated that the modification of the inhibitory tone circuit deeply affects pain modulation during persistent chronic pain states, induced by peripheral nerve injuries. In pink it is shown the circuit between the ParaBrachial Nucleus $(P B N)$ and the Central nucleus of the Amygdala $(C e A)$ that has a prominent role in the affective dimension of pain. Optogenetics has begun to unravel the profound complexity of this circuit and of the specific sub-populations of neurons involved. (B) Diverse sub-populations of sensory neurons in the DRGs form connections at different levels of the substantia gelatinosa (laminae I and II) of the dorsal horn. A list of sub-populations of nociceptive neurons that have a crucial role in pain perception

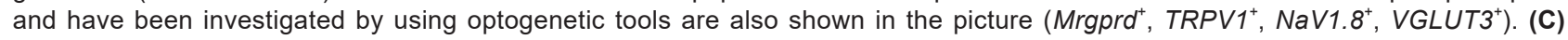
Enlargement of a representative neuron in the DRG, showing the main molecular targets involved in nociception that can be currently targeted by specific photo-controllable drugs (TRP channels in light blue, VGICs in green and MOR in light pink). (D) Optogenetic tools have also been used to elicit responses in peripheral mechano-sensitive cells (Merkel cells and keratinocytes) in the epidermis to investigate the role of non-neuronal cells in the perception of innocuous and painful mechanical stimuli.

sufficient to elicit a painful response $(62,63,65,107-109)$. Moreover, prolonged activation of NaV1.8-positive and TRPV1-positive neurons caused a hypersensitivity that lasted long after the stimulus was removed $(110,111)$. Interestingly, the selective activation of the Vescicular GLUtammate Transporter type 3 (VGLUT3)-positive primary afferents elicited only very mild nocifensive behaviours but exacerbated nociceptive responses in a model of chemotherapy-induced neuropathic pain through the Transient Receptor Potential Melastatin 8 (TRPM8) ion channel (112). Conversely, inhibition of the same neuronal populations (NaV1.8-positive, TRPV1positive) with Arch or HR optogenetic probes alleviates pain behaviours in naïve mice together with murine models of inflammatory and neuropathic pain (Figure 2B) $(62,111,113)$. These results are particularly important in pioneering the use of light as an analgesic, opening to the possibility of the use of optogenetics to treat chronic pain. Furthermore, the combination of optogenetic and chemogenetic techniques refines the selection and classification of neuronal sub-populations that have not been specifically genetically identified yet: the use of resiniferatoxin to ablate TRPV1-positive fibres in a transgenic mice expressing ChR2 in Calcitonin related polypeptide 1 (Calca)-positive neurons has brought to the identification of a novel, specific population of HighThreshold MechanoReceptors (HTMR) with unique endings that can be activated by the pulling of a single hair (114).

Furthermore, optogenetic manipulations are not restricted to neuronal cells: in several recent studies peripheral mechano-sensitive cells in the epidermis have been infected to express excitatory and inhibitory opsins. Activation of Merkel cells and keratinocytes is sufficient to elicit action potential discharge in different types of primary afferents, whereas silencing of these cells decreases the spiking of peripheral sensory neurons in response to natural stimuli, as well as ATP release and 
nocifensive responses to mechanical painful stimuli (Figure 2D) $(67,115,116)$.

Despite revolving mainly around the on/off modulation of whole cell populations, optogenetics has been a keystone in the study of pain circuits, and together with other genetic, electrophysiological and molecular techniques led to the discovery of many important molecular targets for the modulation of pain perception. A more advanced, photopharmacological approach can then be exploited to increase the complexity and capability of research to devise novel approaches to pain modulation and analgesia that can then be translated into therapeutics. To date, only few photo-switchable regulators of nociception have been developed and even less have been described in an in vivo system $(13,91)$. In terms of potential targets involved in the pain pathways, one of the most obvious classes is represented by ion channels. However, of the 215 ion channels that exist in the human genome, with 85 ion channels that have been linked to nociception, only a minor number has been successfully targeted for pain research (117).

TRPV1 is a $\mathrm{Ca}^{2+}$ permeant non-selective cation channel expressed in various subset of populations of primary afferent neurons and with a well-established role in nociception $(118,119)$. To date, optical control of TRPV1 has been investigated and the result is the development of several azo-capsaicin derivatives (AzCAs). These molecules are photo-switchable agonists of TRPV1 channels, they are fairly inactive in the dark and are activated upon irradiation with UV-A light (120). Among these, cis-AzCA4 (121) has been shown to be one of the most effective in activating TRPV1 and to possess a reversible action. In addition, in vivo tests demonstrated a TRPV1-mediated hyperalgesia exerted after the application of this compound (Figure 2C) (16,120,122).

A photo-switchable compound (Optovin) that reversibly activates another member of the TRP channel family, Transient Receptor Potential Ankyrin 1 (TRPA1), has also been developed so far $(123,124)$. This molecule has been used to modulate TRPA1b channels in zebrafish (Figure 2C) (125). Recently, photo-switchable diacylglyerols have also been used to optically-tune the activity of TRPC2, TRPC6 (126) and TRPC3 (127).

GABA-A receptors are chloride-selective pentameric ligand gated ion channels activated by Gamma AmminoButirric Acid (GABA). In post-synaptic neurons, GABA receptors trigger a decrease of action potential firing upon their activation. Given that, GABA-A receptors have been investigated as potential target for the development of anaesthetics $(128,129)$. Photo-compounds that act on GABA-A receptors have been synthetized resembling the structure of Propofol, a lipophilic anaesthetic agent that acts through potentiation of GABA-induced currents (128). These compounds operated as allosteric modulators, potentiating GABA currents in the dark and being inactivated upon application of light. Additional Azobenzene derivatives of propofol were produced (AP1-16) and among these, AP2 showed anaesthetic activity in an in vivo animal model in albino Xenopus laevis tadpoles (128).
Also, the so-called LiGABAR, that is a genetically modified light-controlled GABA receptor, has been developed, so far, by using tethered photopharmacology (130). The resulting design of a transgenic line of mice constitutively expressing LiGABAR, facilitated the development of higher efficient new PTLs (PAG-1C) and finally allowed to control the activity of cortical neurons in mice by using the light (131).

Voltage-gated ion channels (VGICs) play an essential role in the generation of action potentials and in synaptic transmission and represent a privileged target of photopharmacology. They have also been fundamental for the development of the field (132). The photoswitchable azobenzene derivative QAQ is structurally composed of two azo-linked quaternary amines and, together with its derivative QX-314, has been developed on the basis of lidocaine, a local anaesthetic that blocks VGICs $(133,134)$. These compounds are blockers of KV, $\mathrm{NaV}$, and $\mathrm{CaV}$ channels and, importantly, are membraneimpermeable and thus they need to be transported into the cell via TRPV1 channels or P2X receptors, allowing the selective targeting of TRPV1 expressing cells for the optical control of nociception. These molecules have been used, in addition to capsaicin, to selectively block TRPV1-positive nociceptors $(135,136)$. So far, a QAQ derivative has also been developed, namely QENAQ, that is controlled by using visible light. This compound allows to photo-control the pain signalling without issues deriving from invasiveness and with high specificity and fast kinetics (Figure 2C) (137). Another compound (fotocaine) based on azologisation of the local anaesthetic fomocaine has been also developed. Neurophysiological application of this compound has opened up the way to test its applicability as a potential analgesic $(135,136)$.

$\mu$-opioid receptors are GPCRs that activate inhibitory G-proteins. They assemble as homo- and hetero-dimeric complexes and scaffold a variety of proteins. GPCRs are potentially involved in all physiological processes in eukaryotic organisms, including acute and chronic pain (91). Indeed, most of the potent analgesics currently in use act through the $\mu$-opioid receptor. Moreover, they belong to the class A (Rhodopsin-like family) of GPCRs and thus they have been an exclusively amenable class of proteins for the development of phototunable compounds. For these reasons, photo-switchable opioids have been under thorough investigation in the last few years. The usage of such compounds, as possible photo-analgesics, may enable the optical-control of $\mu$-opioid receptors. The first compound that has been developed was an azobenzene derivative of the synthetic $\mu$-opioid receptor agonist Fentanyl (photofentanyl-2 or PF2) (Figure 2C) (138). The development of this compound generated interest in a potential future use of photo-analgesics $(16,139)$.

Photopharmacology is constantly growing and its usage to control nociception is an emerging but interesting field. New compounds are frequently synthetized in order to get accurate control of novel targets (ionotropic glutamate receptors $(37,140)$, metabotropic glutamate receptors $(141,142)$, adrenergic receptors, muscarinic acetylcholine 
receptors, dopamine, histamine, serotonin receptors, calcium and potassium channels and a number of transporters and pumps $(12,13,75))$.

\section{Advancements in light delivery methods}

Optogenetics and photopharmacology have the great potential to dissect the somatosensory circuitry and the key molecular players involved in pain biology and pathobiology $(143,144)$. However, one of the major limitations of these approaches, particularly in behavioural experiments, is the complexity to deliver light especially to neurons in the spinal cord and in the periphery in freely behaving mice (143). Brain imaging and optogenetics in awake rodents with chronic optic fibre implants is currently well established and can be used also in combination with electrophysiology to optically stimulate and record, at the same time, from different neuronal circuits in vivo (Figure 3A, B) $(94,144)$. Imaging peripheral tissues however poses major technical difficulties in the absence of a solid structure like the skull, that can help to stabilise the implants. The first attempts involved peripheral light delivery to the hind paws by implementing optical fibres or Light-Emitting Diode (LED) arrays in cages to target opsin-expressing afferents for behavioural and place aversion tests (Figure 3G) $(63,65,110)$. To overcome the limitations of this approach, and in the effort to target more central structures like the spinal cord, tethered optical fibres have been adapted for peripheral nervous system stimulation. Laserdriven optical fibres have been implanted chronically in the epidural space of the spinal cord, allowing for direct modulation of opsin-expressing peripheral sensory neurons innervating the dorsal horn of the spinal cord, as well as interneurons in the substantia gelatinosa (Figure 3C) $(113,145)$. Another similar approach involves the use of a nerve cuff that surrounds the peripheral nerve: the light stimulation is provided by an optical fibre tethered to the skull and delivered subcutaneously to reach the implanted cuff (Figure 3E) (146). These new technologies have propelled the use of optogenetics to investigate peripheral nociception. However, these implants are still dependent on an apparatus that is partially fixed to the skull, hindering the free movement of the animals. Wireless implantable LED devices for the stimulation of superficial areas in the brain, spinal cord and peripheral tissue have seen a great popularity in the last years. Different laboratories have used similar approaches for the construction of miniaturised probes that utilise microscale LEDs to allow light stimulation in freely behaving rodents (107,109,110,147-149). These implants utilise inductive coupling to remotely power the $\mu$ LEDs, eliminating the need for batteries and circuits and dramatically reducing the dimension of the implants themselves, that can be as small as $10 \mathrm{~mm}^{3}$ and weight as less as $20 \mathrm{mg}$ (Figure 3D, F, H) (110). The most recent versions of these devices use near-field power coupling and radio frequencies transmission to power and activate the LEDs, as well as softer and more durable encapsulation of the microcircuits, strategies that reduce both the fabrication cost and the technical expertise necessary to produce such devices $(109,148,149)$. Further technological improvements of these wireless approaches will make the simultaneous stimulation and recording of responses possible, as it has been demonstrated in the central nervous system (150), and will help to render a more complete picture of the somatosensory coding of multi-modal stimuli in freely moving animals.

\section{Therapeutic potential and challenges of light- based pharmacology}

The possibility to achieve a high spatial and temporal resolution in controlling the signalling of defined neuronal populations throughout the nervous system opens the path towards the development of more effective therapies for disease and pain treatment. Pain management and chronic pain treatment, as stated before, are fundamental problems that are poorly addressed by current treatments and often burdened by unwanted side effects.

Optogenetic and photopharmacological tools employ a spatially defined beam of light as stimulus to elicit a response in the desired target. It is exactly this spatial definition that may be a very effective way to modulate chronic pain in suffering patients (151). The obvious targets to exploit are the numerous ion channels that are expressed centrally and peripherally and are involved in nociception: photo-controllable drugs have been designed to modulate TRPV1, TRPA1, $\mu$-opioid, GABA-A and metabotropic glutamate receptors $(118,120,123,128,137,1$ $39,152,153)$. Photochemical and optogenetic controllers of opioid signalling harbour the most promise in delivering peripheral analgesia without involving central circuits linked to addiction $(53,139)$. Another interesting approach is the use of photo-reversible local anaesthetics that target TRPV1-positive nociceptors (QAQ and QENAQ) and have been effective in controlling pain signalling in behaving rodents $(134,137)$. Moreover, well-established light-based techniques now exist for bidirectional control of primary afferents via transdermal stimulation: these techniques could potentially harbour a future of noninvasive, implant-free optogenetic control of chronic pain disorders (147). A fascinating, similarly non-invasive use of light-based therapy is the prolonged exposure of patients to specific light wavelengths to treat pain and anxiety; this kind of therapy has already been used to control depression in chronic pain and disease suffering patients $(154,155)$, and has been recently associated with profound, opioid-dependent peripheral and central anti-nociception in naïve and neuropathic pain suffering rodents (156).

Despite harbouring great promise, several hurdles have still to be overcome in order to deliver a safe and effective therapy for pain management. The two principal issues in the implementation of light-based therapies are the genetic delivery of the opsins or photo-switches to their targets and the delivery of light to inaccessible organs like the brain and the spinal cord. As stated before, the development of wireless light delivery methods using $\mu \mathrm{LEDs}$, that are miniaturised, injectable and programmable, 


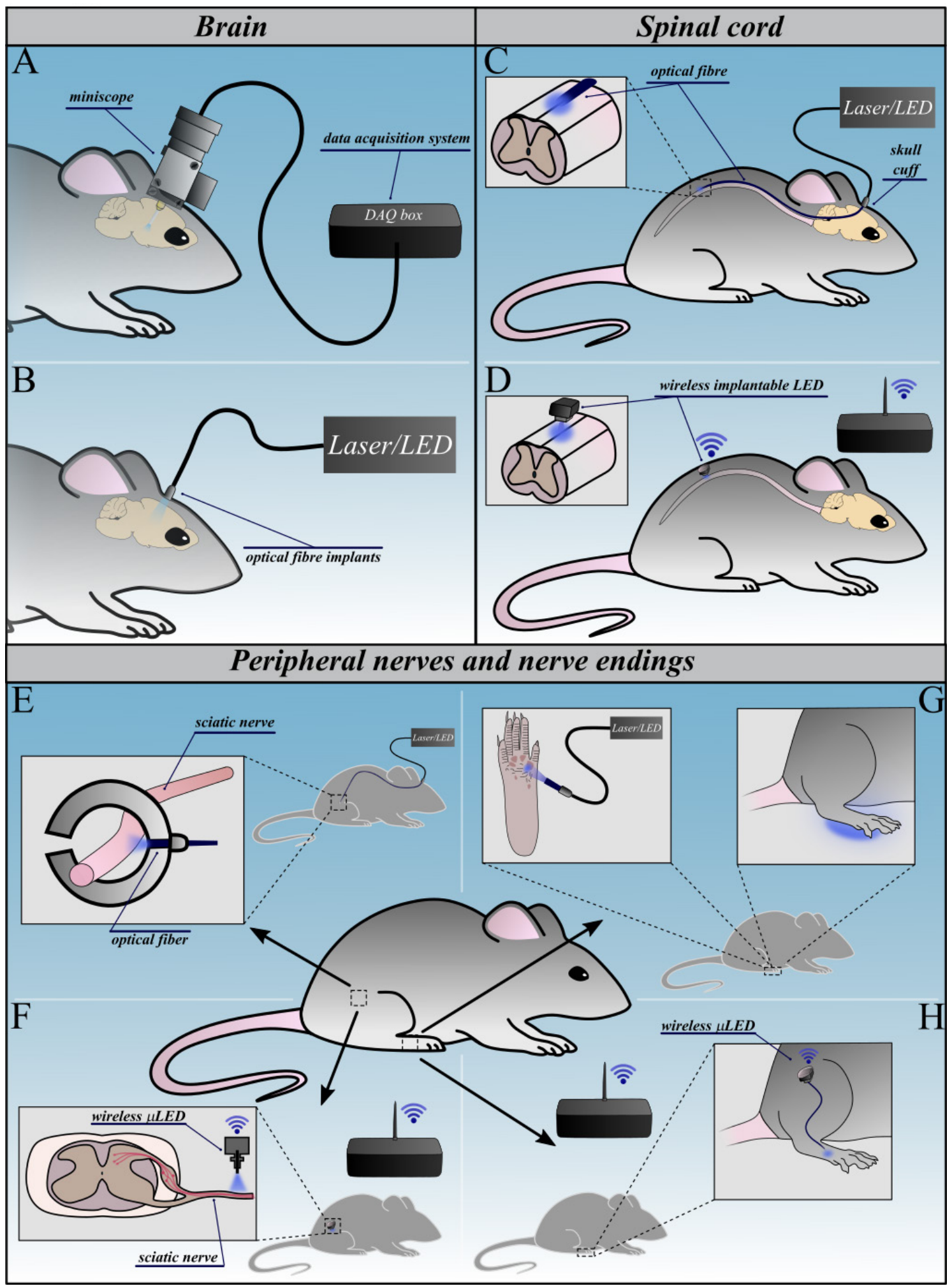

Figure 3. Past, present and future approaches for light delivery within the nervous system. Cartoon illustrating all the different approaches used to deliver light to different regions within the Central and Peripheral Nervous Systems, discussed in this review. (A, B) Light delivery approaches for brain imaging. (A) Head-mounted microscope system. (B) Skull-implanted cuff with an optical fibre cannula; (C, D) Light delivery techniques used in the spinal cord imaging. (C) Skull cuff with implanted epidural flexible light-emitting diode (LED). (D) Wirelessly powered $\mu$ LED device for stimulation of spinal afferents or spinal cord neurons. (E, F) Light delivery approaches for Peripheral Nerves. (E) The sciatic nerve is represented, as an example. Fiber-optic coupled nerve cuffs are implanted subcutaneously and connected to the skull. (F) Small, wireless $\mu$ LED devices can directly deliver light to the nerve. (G, H) Nerve endings light delivery techniques. (G) Transdermal illumination of sensory nerve endings through an external source of light. In the picture two alternative methods are represented (enlargements). (H) $\mu$ LEDs implanted subcutaneously for wireless light-delivery to the area of interests. 
is becoming more and more effective, and these devices allow efficient remote photocontrol with minimal tissue damage $(107,109,147,157,158)$. Concomitant light and drug delivery is currently being explored via a combination between light-emitting and microfluidic devices (159).

Gene therapy is the principal tool to successfully and safely deliver photo-controllable molecules to patients. The use of viral vectors has already been effective in the peripheral delivery of transgenes to patients, albeit most studies addressing chronic pain involve direct production and release of analgesic molecules, like GABA or opioid agonists $(160,161)$. AAV vectors are currently used to express ChR2 in retinal ganglion cells of patients, and Herpes Simplex Virus vectors have been used to successfully deliver gene products in humans through intradermal injections $(162,163)$.

Other current limitations of light-based approaches for therapy are the safeness as well as the transient nature of the expression of opsins and photoswitches. Maximal expression of AAV-delivered proteins takes a few weeks, after which the level decreases: routine administration may solve this problem maintaining optimal expression levels. Delivery of the newly engineered bi-stable opsins may partially solve the problem by eliciting longlasting changes in neuronal activity following low light stimulation (47). Moreover, continuous increase in clinical trials that employ virally mediated gene therapy will boost the improvement of safer vectors for therapeutic treatment, reducing, therefore, the potential occurrence of immune responses.

Thus, despite the critical issues stated before, light-based approaches already represent a powerful and fundamental tool in the study of pain physiology and pathology. Future technological, as well as biological improvements will help to surmount their current obstacles making them a promising candidate for the development of novel therapies in the challenging field of pain management.

\section{Conclusion and future remarks}

Light-based pharmacology and genetics have undergone great development in the past two decades. Researchers from various fields recognise the impact that the implementation of these techniques has on their research, as well as the great clinical potential of these approaches, and new interesting targets and applications are emerging at a swift rate. The further development of more and more specific photo-switchable molecules and optogenetic probes, coupled with the advancements in gene therapy and engineering of non-invasive tools to visualise and manipulate their functions in-situ, may enable selective and powerful therapeutic interventions and will continue to refine the research on complex neuronal circuits and functions. Finally, the high temporal resolution and cell specificity allowed by these techniques offer great potential for the development of phototherapy as a routinary, powerful and personalised approach to pain treatment that could overcome the limitation of conventional pharmacology.

\section{Acknowlegements}

The authors would like to thank Prof. John Wood for the insightful discussion and suggestions during the making of this article. We also thank the core funding from AstraZeneca ("Spinal circuitry of mechanical nociception”) and Wellcome Trust (200183/Z/15/Z)

\section{Conflict of interest}

The authors declare no conflicts of interest in the writing of this paper.

\section{Funding body}

AstraZeneca, Cambridge, UK.

Wellcome Trust - Charitable Health Foundation, London, UK.

\section{References}

1. Pain terms: a list with definitions and notes on usage. Recommended by the IASP Subcommittee on Taxonomy. Pain. 1979 Jun;6(3):249.

2. Nahin RL. Estimates of Pain Prevalence and Severity in Adults: United States, 2012. J Pain. 2015 Aug 1;16(8):769-80.

3. Breivik H, Collett B, Ventafridda V, Cohen R, Gallacher D. Survey of chronic pain in Europe: prevalence, impact on daily life, and treatment. Eur J Pain. 2006 May 20;10(4):287-287.

4. Todd AJ. Neuronal circuitry for pain processing in the dorsal horn. Nat Rev Neurosci. 2010 Dec;11(12):823-36.

5. Peirs C, Seal RP. Neural circuits for pain: recent advances and current views. Science. 2016 Nov 4;354(6312):578-84.

6. von Hehn CA, Baron R, Woolf CJ. Deconstructing the neuropathic pain phenotype to reveal neural mechanisms. Neuron. 2012 Feb 23;73(4):638-52.

7. Markenson JA. Mechanisms of chronic pain. Am J Med. 1996 Jul 31;101(1 A):S6-18.

8. Meacham K, Shepherd A, Mohapatra DP, Haroutounian S. Neuropathic pain: central vs. peripheral mechanisms. Curr Pain Headache Rep. 2017 Jun 1;21(6):28.

9. Saab CY. Chronic pain and brain abnormalities. Chronic Pain and Brain Abnormalities. 2013;1-148.

10. Usoskin D, Furlan A, Islam S, Abdo H, Lönnerberg P, Lou $D$, et al. Unbiased classification of sensory neuron types by large-scale single-cell RNA sequencing. Nat Neurosci. 2015 Jan 1;18(1):145-53.

11. Boyden ES, Zhang F, Bamberg E, Nagel G, Deisseroth K. Millisecond-timescale, genetically targeted optical control of neural activity. Nat Neurosci. 2005;8(9):1263-8.

12. Paoletti P, Ellis-Davies GCR, Mourot A. Optical control of neuronal ion channels and receptors. Nat Rev Neurosci. 2019 Sep 1;20(9):514-32.

13. Hüll K, Morstein J, Trauner D. In vivo photopharmacology. Chem Rev. 2018 Nov 14;118(21):10710-47.

14. Rost BR, Schneider-Warme F, Schmitz D, Hegemann P. Optogenetic tools for subcellular applications in neuroscience. Neuron. 2017 Nov 1;96(3):572-603.

15. Velema WA, Szymanski W, Feringa BL. Photopharmacology: beyond proof of principle. J Am Chem Soc. 2014 Feb 12;136(6):2178-91.

16. Lerch MM, Hansen MJ, van Dam GM, Szymanski W, Feringa BL. Emerging targets in photopharmacology. Angew Chem Int Ed. 2016 Sep 5;55(37):10978-99.

17. Nikolaev DM, Panov MS, Shtyrov AA, Boitsov VM, Vyazmin SY, Chakchir OB, et al. Perspective tools for optogenetics and photopharmacology: from design to implementation. Springer Ser Chem Phys. 2019;119:139-72.

18. Oesterhelt $D$, Stoeckenius W. Rhodopsin-like protein from the purple membrane of Halobacterium halobium. Nat New Biol. 1971 Sep 29;233(39):149-52.

19. Matsuno-Yagi A, Mukohata Y. Two possible roles of bacteriorhodopsin; a comparative study of strains of Halobacterium halobium differing in pigmentation. Biochem Biophys Res Commun. 1977 Sep 9;78(1):237-43. 
20. Nagel G, Ollig D, Fuhrmann M, Kateriya S, Musti AM, Bamberg $E$, et al. Channelrhodopsin-1: a light-gated proton channel in green algae. Science. 2002 Jun 28;296(5577):2395-8.

21. Zemelman B V., Lee GA, Ng M, Miesenböck G. Selective photostimulation of genetically chARGed neurons. Neuron. 2002 Jan 3;33(1):15-22.

22. Lima $S Q$, Miesenböck $G$. Remote control of behavior through genetically targeted photostimulation of neurons. Cell. 2005 Apr 8;121(1):141-52.

23. Banghart M, Borges $\mathrm{K}$, Isacoff $\mathrm{E}$, Trauner D, Kramer RH. Light-activated ion channels for remote control of neuronal firing. Nat Neurosci. 2004 Dec;7(12):1381-6.

24. Aravanis A, Wang L, Zhang F, Meltzer L, Mogri M, Schneider $M$, et al. An optical neural interface: in vivo control of roden motor cortex with integrated fiberoptic and optogenetic technology. J Neural Eng. 2007;4(3):S143-S156.

25. Tye KM, Deisseroth K. Optogenetic investigation of neura circuits underlying brain disease in animal models. Nat Rev Neurosci. 2012 Apr;13(4):251-66.

26. Wang $H$, Vilela M, Winkler A, Tarnawski M, Schlichting I, Yumerefendi $\mathrm{H}$, et al. LOVTRAP: an optogenetic system for photoinduced protein dissociation. Nat Methods. 2016 Aug 30;13(9):755-8

27. Berndt A, Lee SY, Ramakrishnan C, Deisseroth K. Structureguided transformation of channelrhodopsin into a lightactivated chloride channel. Science. 2014;344(6182):420-4.

28. Berndt A, Lee SY, Wietek J, Ramakrishnan C, Steinberg $E E$, Rashid AJ, et al. Structural foundations of optogenetics: determinants of channelrhodopsin ion selectivity. Proc Natl Acad Sci USA. 2016 Jan 26;113(4):822-9.

29. Iyer SM, Vesuna S, Ramakrishnan C, Huynh K, Young S, Berndt A, et al. Optogenetic and chemogenetic strategies for sustained inhibition of pain. Sci Rep. 2016 Aug 3;6:30570.

30. Airan RD, Thompson KR, Fenno LE, Bernstein H, Deisseroth $\mathrm{K}$. Temporally precise in vivo control of intracellular signalling. Nature. 2009 Apr 23;458(7241):1025-9.

31. Schindler SE, McCall JG, Yan P, Hyrc KL, Li M, Tucker CL, et al. Photo-activatable Cre recombinase regulates gene expression in vivo. Sci Rep. 2015 Sep 9:5:13627.

32. Jarrin S, Finn DP. Optogenetics and its application in pain and anxiety research. Neurosci Biobehav Rev. 2019 Oct 1;105:200-11.

33. Bieth J, Vratsanos SM, Wassermann N, Erlanger BF Photoregulation of biological activity by photocromic reagents. II. Inhibitors of acetylcholinesterase. Proc Natl Acad Sci USA. 1969;64(3):1103-6.

34. Deal WJ, Erlanger BF, Nachmansohn D. Photoregulation of biological activity by photochromic reagents. 3 . Photoregulation of bioelectricity by acetylcholine receptor inhibitors. Proc Natl Acad Sci USA. 1969;64(4):1230-4.

35. Fehrentz T, Schönberger M, Trauner D. Optochemica genetics. Angew Chem Int Ed. 2011 Dec 16;50(51):12156-82.

36. Polosukhina A, Litt J, Tochitsky I, Nemargut J, Sychev Y, De Kouchkovsky I, et al. Photochemical restoration of visua responses in blind mice. Neuron. 2012 Jul 26;75(2):271-82.

37. Laprell L, Hüll K, Stawski P, Schön C, Michalakis S, Biel $M$, et al. Restoring light sensitivity in blind retinae using a photochromic AMPA receptor agonist. ACS Chem Neurosci. 2016 Jan 20;7(1):15-20.

38. Miesenböck G. Optogenetic control of cells and circuits Annu Rev Cell Dev Biol. 2011 Nov 10;27(1):731-58.

39. Nagel G, Szellas T, Huhn W, Kateriya S, Adeishvili N, Berthold $\mathrm{P}$, et al. Channelrhodopsin-2, a directly light-gated cation-selective membrane channel. Proc Natl Acad Sci USA. 2003 Nov 25;100(SUPPL. 2):13940-5.

40. Gradinaru V, Mogri M, Thompson KR, Henderson JM, Deisseroth K. Optical deconstruction of parkinsonian neura circuitry. Science. 2009 Apr 17;324(5925):354-9.

41. Zhang F, Wang LP, Brauner M, Liewald JF, Kay K, Watzke N, et al. Multimodal fast optical interrogation of neural circuitry.
Nature. 2007 Apr 5;446(7136):633-9.

42. Chow BY, Han X, Dobry AS, Qian X, Chuong AS, Li M, et al. High-performance genetically targetable optical neural silencing by light-driven proton pumps. Nature. 2010 Jan 7;463(7277):98-102.

43. Berndt A, Schoenenberger P, Mattis J, Tye KM, Deisseroth K, Hegemann P, et al. High-efficiency channelrhodopsins for fast neuronal stimulation at low light levels. Proc Natl Acad Sci USA. 2011 May 3;108(18):7595-600

44. Gunaydin LA, Yizhar O, Berndt A, Sohal VS, Deisseroth K, Hegemann P. Ultrafast optogenetic control. Nat Neurosci. 2010 Mar;13(3):387-92.

45. Zhang F, Prigge M, Beyrière F, Tsunoda SP, Mattis J, Yizhar $O$, et al. Red-shifted optogenetic excitation: a tool for fast neural control derived from Volvox carteri. Nat Neurosci. 2008 Jun;11(6):631-3.

46. Chuong AS, Miri ML, Busskamp V, Matthews GAC, Acker LC, Sørensen AT, et al. Noninvasive optical inhibition with a red-shifted microbial rhodopsin. Nat Neurosci. 2014;17(8):1123-9.

47. Berndt A, Yizhar O, Gunaydin LA, Hegemann P, Deisseroth K. Bi-stable neural state switches. Nat Neurosci. 2009 Feb;12(2):229-34.

48. Oh E, Maejima T, Liu C, Deneris E, Herlitze S. Substitution of 5-HT1A receptor signaling by a light-activated $\mathrm{G}$ proteincoupled receptor. J Biol Chem. 2010 Oct 1;285(40):30825-36.

49. Gunaydin LA, Grosenick L, Finkelstein JC, Kauvar I V., Fenno LE, Adhikari A, et al. Natural neural projection dynamics underlying social behavior. Cell. 2014 Jun 19;157(7):1535-51.

50. Li P, Rial D, Canas PM, Yoo JH, Li W, Zhou X, et al. Optogenetic activation of intracellular adenosine A2A receptor signaling in the hippocampus is sufficient to trigger CREB phosphorylation and impair memory. Mol Psychiatry. 2015 Nov 1;20(11):1339-49.

51. van Wyk M, Pielecka-Fortuna J, Löwel S, Kleinlogel S. Restoring the ON switch in blind retinas: opto-mGluR6, a next-generation, cell-tailored optogenetic tool. PLoS Biol. 2015 May 7;13(5):e1002143.

52. Barish PA, Xu Y, Li J, Sun J, Jarajapu YPR, Ogle WO. Design and functional evaluation of an optically active $\mu$-opioid receptor. Eur J Pharmacol. 2013 Apr 5;705(1-3):42-8.

53. Siuda ER, Copits BA, Schmidt MJ, Baird MA, Al-Hasani R, Planer WJ, et al. Spatiotemporal Control of Opioid Signaling and Behavior. Neuron. 2015 May 20;86(4):923-35.

54. Luo L, Callaway EM, Svoboda K. Genetic Dissection of Neural Circuits. Neuron. 2008 Mar 13;57(5):634-60.

55. Zhang F, Gradinaru V, Adamantidis AR, Durand R, Airan $\mathrm{RD}$, De Lecea $\mathrm{L}$, et al. Optogenetic interrogation of neural circuits: technology for probing mammalian brain structures. Nat Protoc. 2010 Mar;5(3):439-56.

56. Zeng $\mathrm{H}$, Madisen L. Mouse transgenic approaches in optogenetics. Prog Brain Res. 2012;196:193-213.

57. Zhang F, Wang LP, Boyden ES, Deisseroth K. Channelrhodopsin-2 and optical control of excitable cells. Nat Methods. 2006 Oct;3(10):785-92.

58. Nagy A. Cre recombinase: the universal reagent for genome tailoring. Genesis. 2000 Feb 1;26(2):99-109.

59. Branda CS, Dymecki SM. Talking about a revolution: The impact of site-specific recombinases on genetic analyses in mice. Dev Cell. 2004 Jan;6(1):7-28.

60. Schnütgen $F$, Doerflinger $N$, Calléja $C$, Wendling $O$, Chambon P, Ghyselinck NB. A directional strategy for monitoring Cre-mediated recombination at the cellular level in the mouse. Nat Biotechnol. 2003 May 1;21(5):562-5.

61. Cardin JA, Carlén M, Meletis K, Knoblich U, Zhang F, Deisseroth $\mathrm{K}$, et al. Driving fast-spiking cells induces gamma rhythm and controls sensory responses. Nature. 2009 Jun 4;459(7247):663-7.

62. Li B, Yang XY, Qian FP, Tang M, Ma C, Chiang LY. A novel analgesic approach to optogenetically and specifically inhibit 
pain transmission using TRPV1 promoter. Brain Res. 2015;1609(1):12-20.

63. Daou I, Tuttle AH, Longo G, Wieskopf JS, Bonin RP, Ase $A R$, et al. Remote optogenetic activation and sensitization of pain pathways in freely moving mice. J Neurosci Res. 2013;33(47):18631-40.

64. Gong S, Doughty M, Harbaugh CR, Cummins A, Hatten ME, Heintz N, et al. Targeting Cre recombinase to specific neuron populations with bacterial artificial chromosome constructs. J Neurosci Res. 2007 Sep 12;27(37):9817-23.

65. Beaudry H, Daou I, Ase AR, Ribeiro-Da-Silva A, Séguela P. Distinct behavioral responses evoked by selective optogenetic stimulation of the major TRPV1+ and MrgD+ subsets of C-fibers. Pain. 2017;158(12):2329-39.

66. Madisen L, Mao T, Koch H, Zhuo JM, Berenyi A, Fujisawa $\mathrm{S}$, et al. A toolbox of Cre-dependent optogenetic transgenic mice for light-induced activation and silencing. Nat Neurosci. 2012 May;15(5):793-802.

67. Baumbauer KM, Deberry JJ, Adelman PC, Miller RH, Hachisuka $\mathrm{J}$, Lee $\mathrm{KH}$, et al. Keratinocytes can modulate and directly initiate nociceptive responses. eLife. 2015 Sep 2;4:e09674.

68. Madisen L, Garner AR, Shimaoka D, Chuong AS, Klapoetke $\mathrm{NC}$, Li L, et al. Transgenic mice for intersectional targeting of neural sensors and effectors with high specificity and performance. Neuron. 2015 Mar 4;85(5):942-58.

69. Bourane S, Duan B, Koch SC, Dalet A, Britz O, GarciaCampmany L, et al. Gate control of mechanical itch by a subpopulation of spinal cord interneurons. Science. 2015 Oct 30;350(6260):550-4.

70. Robertson SD, Plummer NW, De Marchena J, Jensen P. Developmental origins of central norepinephrine neuron diversity. Nature Neuroscience. 2013 Aug;16(8):1016-23.

71. Fenno LE, Mattis J, Ramakrishnan C, Hyun M, Lee SY, He M, et al. Targeting cells with single vectors using multiple-feature Boolean logic. Nat Methods. 2014 Jun 8;11(7):763-72.

72. Brieke C, Rohrbach F, Gottschalk A, Mayer G, Heckel A. Light-controlled tools. Angew Chem Int Ed. 2012 Aug 20;51(34):8446-76.

73. Ellis-Davies GCR. Caged compounds: Photorelease technology for control of cellular chemistry and physiology. Nat Methods. 2007 Aug 30;4(8):619-28.

74. Klán P, Šolomek T, Bochet CG, Blanc A, Givens R, Rubina $M$, et al. Photoremovable protecting groups in chemistry and biology: reaction mechanisms and efficacy. Chem Rev. 2013 Jan 9;113(1):119-91.

75. Broichhagen J, Frank JA, Trauner D. A Roadmap to success in photopharmacology. Acc Chem Res. $2015 \mathrm{Jul}$ 21;48(7):1947-60.

76. Mutter NL, Volarić J, Szymanski W, Feringa BL, Maglia G. Reversible photocontrolled nanopore assembly. J Am Chem Soc. 2019 Sep 11;141(36):14356-63.

77. Morstein J, Trauner D. New players in phototherapy: photopharmacology and bio-integrated optoelectronics. Curr Opin Chem Biol. 2019 Jun 1;50:145-51.

78. Mehta ZB, Johnston NR, Nguyen-Tu MS, Broichhagen J, Schultz P, Larner DP, et al. Remote control of glucose homeostasis in vivo using photopharmacology. Sci Rep. 2017;7(1):291.

79. Yeoh YQ, Yu J, Polyak SW, Horsley JR, Abell AD. Photopharmacological control of cyclic antimicrobial peptides. Chembiochem. 2018 Dec 18;19(24):2591-7.

80. Sansalone L, Bratsch-Prince J, Tang S, Captain B, Mott DD, Raymo FM. Photopotentiation of the GABAA receptor with caged diazepam. Proc Natl Acad Sci USA. 2019 Oct 15;116(42):21176-84

81. Qazi R, Gomez AM, Castro DC, Zou Z, Sim JY, Xiong $Y$, et al. Wireless optofluidic brain probes for chronic neuropharmacology and photostimulation. Nat Biomed Eng. 2019 Aug 1;3(8):655-69.

82. Mayer G, Hechel A. Biologically active molecules with a "light switch." Angew Chem Int Ed. 2006 Jul 24;45(30):4900-21.
83. Gautier A, Gauron C, Volovitch M, Bensimon D, Jullien L, Vriz S. How to control proteins with light in living systems. Nat Chem Biol. 2014;10(7):533-41.

84. Kamiya H. Photochemical inactivation analysis of temporal dynamics of postsynaptic native AMPA receptors in hippocampal slices. J Neurosci. 2012 May 9;32(19):6517-24.

85. Hansen MJ, Velema WA, Lerch MM, Szymanski W, Feringa $\mathrm{BL}$. Wavelength-selective cleavage of photoprotecting groups: Strategies and applications in dynamic systems. Chem Soc Rev. 2015 Jun 7;44(11):3358-77.

86. Peterson JA, Wijesooriya C, Gehrmann EJ, Mahoney KM, Goswami PP, Albright TR, et al. Family of BODIPY Photocages Cleaved by Single Photons of Visible/NearInfrared Light. J Am Chem Soc. 2018 Jun 13;140(23):7343-6.

87. Jedlitzke B, Yilmaz Z, Dörner W, Mootz HD. Photobodies: light-activatable single-domain antibody fragments. Angew Chem Int Ed. 2020 Jan 20;59(4):1506-10.

88. Hermanson GT. Bioconjugate techniques: 3rd edn. Elsevier Inc.; 2013. p. 229-58.

89. Krishnamurthy VM, Semetey V, Bracher PJ, Shen N, Whitesides GM. Dependence of effective molarity on linker length for an intramolecular protein-ligand system. J Am Chem Soc. 2007 Feb 7;129(5):1312-20.

90. Yasuike N, Lu H, Xia P, Woolley GA. Intramolecular crosslinking of proteins with azobenzene-based cross-linkers. Methods Enzymol. 2019 Jan 1;624:129-49.

91. Gazerani P. Shedding light on photo-switchable analgesics for pain. Pain management. 2017 Mar 1;7(2):71-4.

92. Carr FB, Zachariou V. Nociception and pain: Lessons from optogenetics. Front Behav Neurosci. 2014 Mar 25;8:69.

93. Tovote P, Fadok JP, Lüthi A. Neuronal circuits for fear and anxiety. Nat Rev Neurosci. 2015 Jun 26;16(6):317-31.

94. Corder G, Ahanonu B, Grewe BF, Wang D, Schnitzer MJ, Scherrer G. An amygdalar neural ensemble that encodes the unpleasantness of pain. Science. 2019 Jan 18;363(6424):276-81.

95. Kiritoshi T, Ji G, Neugebauer V. Rescue of impaired mGluR5driven endocannabinoid signaling restores prefrontal cortical output to inhibit pain in arthritic rats. J Neurosci. 2016 Jan 20;36(3):837-50.

96. Zhang Z, Gadotti VM, Chen L, Souza IA, Stemkowski $\mathrm{PL}$, Zamponi GW. Role of prelimbic GABAergic circuits in sensory and emotional aspects of neuropathic pain. Cell Rep. 2015 Aug 4;12(5):752-9.

97. Huang J, Gadotti VM, Chen L, Souza IA, Huang S, Wang D, et al. A neuronal circuit for activating descending modulation of neuropathic pain. Nat Neurosci. 2019 Oct 1;22(10):1659-68.

98. Mcdonald AJ. Cortical pathways to the mammalian amygdala. Prog Neurobiol. 1998 Jun 27;55(3):257-332.

99. Neugebauer V. Amygdala pain mechanisms. Handb Exp Pharmacol. 2015;227:261-84.

100. Bernard JF, Besson JM. The spino(trigemino) pontoamygdaloid pathway: electrophysiological evidence for an involvement in pain processes. J Neurophysiol. 1990;63(3):473-90.

101. Sugimura YK, Takahashi Y, Watabe AM, Kato F. Synaptic and network consequences of monosynaptic nociceptive inputs of parabrachial nucleus origin in the central amygdala. J Neurophysiol. 2016 Jun 1;115(6):2721-39.

102. Crock LW, Kolber BJ, Morgan CD, Sadler KE, Vogt SK, Bruchas MR, et al. Central amygdala metabotropic glutamate receptor 5 in the modulation of visceral pain. $\mathrm{J}$ Neurosci. 2012 Oct 10;32(41):14217-26.

103. Li JN, Sheets PL. Spared nerve injury differentially alters parabrachial monosynaptic excitatory inputs to molecularly specific neurons in distinct subregions of the central amygdala. Pain. 2020 Jan 1;161(1):166-76.

104. Abraira VE, Ginty DD. The sensory neurons of touch. Neuron. 2013 Aug 21;79(4):618-39.

105. Montgomery KL, Iyer SM, Christensen AJ, Deisseroth K, Delp SL. Beyond the brain: optogenetic control in the spinal 
cord and peripheral nervous system. Sci Transl Med. 2016 May 4;8(337).

106. Wang H, Zylka MJ. Mrgprd-expressing polymodal nociceptive neurons innervate most known classes of substantia gelatinosa neurons. J Neurosci. 2009 Oct 21;29(42):13202-9.

107. Park S II, Brenner DS, Shin G, Morgan CD, Copits BA, Chung HU, et al. Soft, stretchable, fully implantable miniaturized optoelectronic systems for wireless optogenetics. Nat Biotechnol. 2015 Dec 1;33(12):1280-6.

108. Mishra SK, Tisel SM, Orestes P, Bhangoo SK, Hoon MA. TRPV1-lineage neurons are required for thermal sensation. EMBO J. 2011 Feb 2;30(3):582-93.

109. Samineni VK, Yoon J, Crawford KE, Jeong YR, McKenzie KC, Shin G, et al. Fully implantable, battery-free wireless optoelectronic devices for spinal optogenetics. Pain. 2017 Nov 1;158(11):2108-16.

110. Iyer SM, Montgomery KL, Towne C, Lee SY, Ramakrishnan $\mathrm{C}$, Deisseroth $\mathrm{K}$, et al. Virally mediated optogenetic excitation and inhibition of pain in freely moving nontransgenic mice. Nat Biotechnol. 2014;32(3):274-8.

111. Daou I, Beaudry H, Ase AR, Wieskopf JS, Ribeiro-da-Silva A, Mogil JS, et al. Optogenetic silencing of Nav1.8-positive afferents alleviates inflammatory and neuropathic pain eNeuro. 2016;3(1):702-5.

112. Draxler P, Honsek SD, Forsthuber L, Hadschieff V, Sandkühler J. VGluT3+ primary afferents play distinct roles in mechanical and cold hypersensitivity depending on pain etiology. J Neurosci. 2014 Sep 3;34(36):12015-28.

113. Bonin RP, Wang F, Desrochers-Couture M, Ga, secka A, Boulanger ME, Côté DC, et al. Epidural optogenetics for controlled analgesia. Mol Pain. 2016 Feb 27;12.

114. Ghitani N, Barik A, Szczot M, Thompson JH, Li C, Le Pichon CE, et al. Specialized mechanosensory nociceptors mediating rapid responses to hair pull. Neuron. 2017 Aug 16;95(4):944-954.e4

115. Maksimovic S, Nakatani M, Baba Y, Nelson AM, Marshall $\mathrm{KL}$, Wellnitz SA, et al. Epidermal Merkel cells are mechanosensory cells that tune mammalian touch receptors. Nature. 2014;509(7502):617-21.

116. Moehring F, Cowie AM, Menzel AD, Weyer AD, Grzybowsk $\mathrm{M}$, Arzua $\mathrm{T}$, et al. Keratinocytes mediate innocuous and noxious touch via ATP-P2X4 signaling. eLife. 2018 Jan 16;7.

117. Skerratt SE, West CW. Ion channel therapeutics for pain Channels. 2015 Jan 1;9(6):344-51.

118. Zussy C, Gómez-Santacana X, Rovira X, De Bundel $D$, Ferrazzo S, Bosch D, et al. Dynamic modulation of inflammatory pain-related affective and sensory symptoms by optical control of amygdala metabotropic glutamate receptor 4. Mol Psychiatry. 2018 Mar 1;23(3):509-20.

119. Frias B, Merighi A. Capsaicin, nociception and pain Molecules. 2016 Jun 1;21(6)

120. Frank JA, Moroni M, Moshourab R, Sumser M, Lewin GR, Trauner D. Photoswitchable fatty acids enable optical control of TRPV1. Nat Commun. 2015 May 22;6.

121. Konrad DB, Frank JA, Trauner D. Synthesis of redshifted azobenzene photoswitches by late-stage functionalization. Chem Eur J. 2016 Mar 18;22(13):4364-8.

122. Gilbert D, Funk K, Dekowski B, Lechler R, Keller S, Möhrlen $F$, et al. Caged capsaicins: new tools for the examination of TRPV1 channels in somatosensory neurons. Chembiochem. 2007 Jan;8(1):89-97.

123. Kokel D, Cheung CYJ, Mills R, Coutinho-Budd J, Huang L, Setola V, et al. Photochemical activation of TRPA1 channels in neurons and animals. Nat Chem Biol. 2013 Apr;9(4):257-63.

124. Fajardo O, Friedrich RW. Optopharmacology: A light switch for pain. Nat Chem Biol. 2013 Apr;9(4):219-20.

125. Lam PY, Mendu SK, Mills RW, Zheng B, Padilla H, Milan DJ, et al. A high-conductance chemo-optogenetic system based on the vertebrate channel Trpa1b. Sci Rep. 2017 Dec $1 ; 7(1): 11839$.
126. Leinders-Zufall T, Storch U, Bleymehl K, Mederos y Schnitzler M, Frank JA, Konrad DB, et al. PhoDAGs enable optical control of diacylglycerol-sensitive transient receptor potential channels. Cell Chem Biol. 2018 Feb 15;25(2):215-223.e3.

127. Lichtenegger M, Tiapko O, Svobodova B, Stockner T, Glasnov TN, Schreibmayer W, et al. An optically controlled probe identifies lipid-gating fenestrations within the TRPC3 channel article. Nat Chem Biol. 2018 Apr 1;14(4):396-404.

128. Stein M, Middendorp SJ, Carta V, Pejo E, Raines DE, Forman SA, et al. Azo-propofols: photochromic potentiators of GABA a receptors. Angew Chem Int Ed. 2012 Oct 15;51(42):10500-4.

129. Lutz T, Wein T, Höfner G, Pabel J, Eder M, Dine J, et al. Development of new photoswitchable azobenzene based $\mathrm{Y}$-aminobutyric acid (GABA) uptake inhibitors with distinctly enhanced potency upon photoactivation. J Med Chem. 2018 Jul 26;61(14):6211-35.

130. Lin WC, Davenport CM, Mourot A, Vytla D, Smith CM, Medeiros KA, et al. Engineering a light-regulated GABAA receptor for optical control of neural inhibition. ACS Chem Biol. 2014 Jul 18;9(7):1414-9.

131. Lin WC, Tsai MC, Davenport CM, Smith CM, Veit J, Wilson $\mathrm{NM}$, et al. A comprehensive optogenetic pharmacology toolkit for in vivo control of GABAA receptors and synaptic inhibition. Neuron. 2015 Dec 2;88(5):879-91.

132. McKenzie CK, Sanchez-Romero I, Janovjak H. Flipping the photoswitch: ion channels under light control. Adv Exp Med Biol. 2015;869:101-17.

133. Mourot A, Tochitsky I, Kramer RH. Light at the end of the channel: optical manipulation of intrinsic neuronal excitability with chemical photoswitches. Front Mol Neurosci. 2013 Mar 6;6:5

134. Mourot A, Fehrentz T, Le Feuvre Y, Smith CM, Herold C, Dalkara D, et al. Rapid optical control of nociception with an ionchannel photoswitch. Nat Methods. 2012 Apr;9(4):396-402.

135. Binshtok AM, Gerner P, Oh SB, Puopolo M, Suzuki S, Roberson DP, et al. Coapplication of lidocaine and the permanently charged sodium channel blocker QX-314 produces a long-lasting nociceptive blockade in rodents. Anesthesiology. 2009;111(1):127-37.

136. Schoenberger M, Damijonaitis A, Zhang Z, Nagel D, Trauner D. Development of a new photochromic ion channel blocker via azologization of fomocaine. ACS Chem Neurosci. 2014 Jul 16;5(7):514-8.

137. Mourot A, Herold C, Kienzler MA, Kramer RH. Understanding and improving photo-control of ion channels in nociceptors with azobenzene photo-switches. Br J Pharmacol. 2018 Jun 1;175(12):2296-311

138. Römpler $H$, Stäubert $C$, Thor D, Schulz A, Hofreiter M, Schöneberg T. G protein-coupled time travel: evolutionary aspects of GPCR research. Mol Interv. 2007 Feb;7(1):17-25.

139. Schönberger M, Trauner D. A photochromic agonist for $\mu$-opioid receptors. Angew Chem Int Ed. 2014 Mar 17;53(12):3264-7.

140. Levitz J, Popescu AT, Reiner A, Isacoff EY. A toolkit for orthogonal and in vivo optical manipulation of ionotropic glutamate receptors. Front Mol Neurosci. 2016 Feb 2;9:2

141. Goudet C, Rovira X, Llebaria A. Shedding light on metabotropic glutamate receptors using optogenetics and photopharmacology. Curr Opin Pharmacol. 2018 Feb 1;38:8-15.

142. Levitz J, Broichhagen J, Leippe P, Konrad D, Trauner $D$, Isacoff EY. Dual optical control and mechanistic insights into photoswitchable group II and III metabotropic glutamate receptors. Proc Natl Acad Sci USA. 2017 Apr 25;114(17):E3546-54.

143. Mickle AD, Gereau RW. A bright future? Optogenetics in the periphery for pain research and therapy. Pain. 2018 Sep 1;159:S65-73.

144. Copits BA, Pullen MY, Gereau RW. Spotlight on pain: Optogenetic approaches for interrogating somatosensory circuits. Pain. 2016 Aug 19;157(11):2424-33.

145. Christensen AJ, lyer SM, François A, Vyas S, Ramakrishnan C, 
Vesuna S, et al. In Vivo Interrogation of Spinal Mechanosensory Circuits. Cell Rep. 2016 Nov 1;17(6):1699-710.

146. Towne C, Montgomery KL, Iyer SM, Deisseroth K, Delp SL. Optogenetic Control of Targeted Peripheral Axons in Freely Moving Animals. PLoS ONE. 2013 Aug 21;8(8).

147. Montgomery KL, Yeh AJ, Ho JS, Tsao V, lyer SM, Grosenick $\mathrm{L}$, et al. Wirelessly powered, fully internal optogenetics for brain, spinal and peripheral circuits in mice. Nat Methods. 2015 Sep 29;12(10):969-74.

148. Samineni VK, Mickle AD, Yoon J, Grajales-Reyes JG, Pullen MY, Crawford KE, et al. Optogenetic silencing of nociceptive primary afferents reduces evoked and ongoing bladder pain. Sci Rep. 2017 Dec 1;7(1).

149. Shin G, Gomez AM, Al-Hasani R, Jeong YR, Kim J, Xie $Z$, et al. Flexible Near-Field Wireless Optoelectronics as subdermal implants for broad applications in optogenetics. Neuron. 2017 Feb 8;93(3):509-521.e3.

150. Lu L, Gutruf P, Xia L, Bhatti DL, Wang X, Vazquez-Guardado $A$, et al. Wireless optoelectronic photometers for monitoring neuronal dynamics in the deep brain. Proc Natl Acad Sci USA. 2018 Feb 13;115(7):E1374-83.

151. Beaudry H, Daou I, Ribeiro-da-Silva A, Séguéla P. Wil optogenetics be used to treat chronic pain patients? Pain Manag. $2017 \mathrm{Jul}$ 1;7(4):269-78.

152. Stein M, Breit A, Fehrentz T, Gudermann T, Trauner D. Optical control of TRPV1 channels. Angew Chem Int Ed. 2013 Sep 9;52(37):9845-8.

153. Font J, López-Cano M, Notartomaso S, Scarselli P, Di Pietro $\mathrm{P}$, Bresolí-Obach R, et al. Optical control of pain in vivo with a photoactive mGlu5 receptor negative allosteric modulator. eLife. 2017 Apr 11;6.

154. Golden RN, Gaynes BN, Ekstrom RD, Hamer RM, Jacobsen FM, Suppes T, et al. The efficacy of light therapy in the treatment of mood disorders: a review and meta-analysis of the evidence. Am J Psychiatry. 2005 Apr;162(4):656-62.
155. Figueiro MG, Plitnick BA, Lok A, Ejones GE, Higgins $P$, Rhornick TR, et al. Tailored lighting intervention improves measures of sleep, depression, and agitation in persons with Alzheimer's disease and related dementia living in long-term care facilities. Clin Interv Aging. 2014 Sep 12;9:1527-37.

156. Ibrahim MM, Patwardhan A, Gilbraith KB, Moutal A, Yang $X$, Chew LA, et al. Long-lasting antinociceptive effects of green light in acute and chronic pain in rats. Pain. 2017 Feb 1;158(2):347-60.

157. Park S II, Shin G, McCall JG, Al-Hasani R, Norrisf A, Xia $L$, et al. Stretchable multichannel antennas in soft wireless optoelectronic implants for optogenetics. Proc Natl Acad Sci USA. 2016 Dec 13;113(50):E8169-77.

158. Kim T II, McCall JG, Jung YH, Huang X, Siuda ER, Li $Y$, et al. Injectable, cellular-scale optoelectronics with applications for wireless optogenetics. Science. $2013 \mathrm{Apr}$ 12;340(6129):211-6.

159. Jeong JW, McCall JG, Shin G, Zhang Y, Al-Hasani R, Kim $M$, et al. Wireless optofluidic systems for programmable in vivo pharmacology and optogenetics. Cell. 2015 Aug 1;162(3):662-74.

160. Chattopadhyay M, Mata M, Fink DJ. Vector-mediated release of GABA attenuates pain-related behaviors and reduces Na V1.7 in DRG neurons. Eur J Pain. 2011 Oct;15(9):913-20.

161. Braz J, Beaufour C, Coutaux A, Epstein AL, Cesselin $F$, Hamon M, et al. Therapeutic efficacy in experimental polyarthritis of viral-driven enkephalin overproduction in sensory neurons. J Neurosci. 2001 Oct 15;21(20):7881-8.

162. Fink DJ, Wechuck J, Mata M, Glorioso JC, Goss J, Krisky D, et al. Gene therapy for pain: results of a phase I clinical trial. Ann Neurol. 2011 Aug;70(2):207-12.

163. Wolfe D, Mata M, Fink DJ. A human trial of HSV-mediated gene transfer for the treatment of chronic pain. Gene Ther. 2009;16(4):455-60. 